\title{
Design of Community-Based Transdisciplinary Learning for Social Studies Teachers in the Diverse School Contexts, Northern of Thailand
}

\author{
Charin Mangkhang ${ }^{1}$ \\ ${ }^{1}$ Faculty of Education, Chiang Mai University, Thailand \\ Correspondence: Charin Mangkhang, Faculty of Education, Chiang Mai University. 239 Huay Kaew Rd, Suthep, \\ Mueang District, Chiang Mai, Thailand 50200. E-mail: charin.mangkhang@cmu.ac.th
}

Received: February 2, 2021 Accepted: March 16, 2021 Online Published: April 6, 2021

doi:10.5539/jel.v10n3p17 URL: https://doi.org/10.5539/jel.v10n3p17

\begin{abstract}
The objectives of this study are: 1) to study problems and the needs in community-based transdisciplinary learning for social studies teachers in the diverse school contexts, Northern of Thailand 2) to develop and find the efficiency of handbook of community-based transdisciplinary learning for social studies teachers in the diverse school contexts, Northern of Thailand and 3) to examine the implementation results of the handbook. This research is based on the research foundation of a mixed method in education research. The population involved in this study included 1) educational connoisseurship of area-based who are selected by means of purposive sampling, from not less than 5 persons and 2) social studies teachers in the Northern-region provinces of Thailand who are selected by means of accidental sampling, from not less than 334 persons. The research instruments are: 1) a questionnaire on problems and the needs in community-based transdisciplinary learning 2) an appropriateness assessment form on the handbook and 3) an evaluation form of teacher professional competence in community-based transdisciplinary learning. The qualitative data are analyzed and shown on content analysis and descriptive analysis. The quantitative statistics employed for data analysis are mean and standard deviation through statistical program. The research findings revealed as follows;

1) Problems and the needs: teacher professional competence needs to be improved in community-based transdisciplinary learning through 7 skills, namely; Integrated learning Management, Technology Integrated Learning, Integrating Ethics Learning, Community Resource Management, Transdisciplinary Innovation Integrated Learning, Creative Educational Measurement Design, and Competency of Networking skill.

2) The result of handbook development: "SOCIAL Action Learning Model", includes 6 steps, should be implemented in community-based transdisciplinary learning for social studies teachers. Due to the evaluation of the handbook, the result is at the highest level of appropriation $(\bar{x}=4.58$, S.D. $=0.57)$

3 ) The result of handbook using: the handbook of community-based transdisciplinary learning for social studies teachers found the evaluation result at a high level $(\bar{x}=3.96$, S.D. $=0.89)$
\end{abstract}

Keywords: community-based transdisciplinary learning, social studies, diverse school contexts

\section{Introduction}

The concept of Inclusive Education, Sufficiency Economy, and All for Education adopted the 2030 Agenda for Sustainable Development establishes equality in learning for local community students with inclusive education, on the ground that local wisdom is cultivated and related to daily life of students. The way community members acquire various answers to explore or explain their questions conveys the essence of learning which its key is practical applications of learning. The integral learning for students in the local community may not only happen in the classroom, it also occurs through "the process to obtain answers" which broaden their life skills. Having love and cherish in their local community, they have better understanding by telling the story of themselves or early stages of community, satisfaction with community life, and the value of its resource which motivates pride taken in the local people and local community (Mangkhang et al., 2015).

Construction participatory process in area-based curriculum designing should be genuinely interested in the gathering of community members in order to deliberate over the target population. The development of learning management handbook responses the community needs on the reason that it leads toward the management of community knowledge and systemic community databases as local learning resources about the way of living 
and cultural ecology. The community has expectations on sustainably traditional culture way of living which will be echoed through narration to future youth and children. This is agreeable to the theoretical concept of sustainable development that requires a place-based approach for assessing local needs without degrading community resources for future use. Learning management must increase the focus on the development of self-reliance and self-management in the local community capacity based on knowledge, moral and ethics, without destroying quality of life and environment, coordinated with national strategy, "Stability, Prosperity, and Sustainability" Presently, the way of learning must carry out the association through various realms of knowledge designed to meet Global Citizenship in the 21 st Century, transdisciplinarity, therefore, is considered a new form of learning and problem solving, related to cooperation between different sections of society, including educational institutions, that helps to meet complex challenges of society (Regeer, 2002). The objective of transdisciplinary is to understand the present world, in all of its complexities, instead of focusing on one part of it (Nicolescu, 1997). Transdisciplinary knowledge is a new kind of knowledge that complements traditional, mono-disciplinary knowledge. A new intellectual space is formed. Therein resides a gradual cross-fertilization resulting from the convergence of different paths (Lattanzi, 1998). Nicolescu (1997) cites that transdisciplinarity concerns in the center of any civilized society, i.e., Community-Based Transdisciplinary Learning in Social Studies (CBTDSS).

According to Smith (2005), such lack of understanding about sustainable development can hold back the strengthening in "Green Citizenship" Knowledge transfer is a key dimension of a learning organization to improve the effectiveness and efficiency of demonstrable outcomes in daily life and life quality. It also reinforces common awareness to encourage valued demonstration, self-reliance, and creates intellectual capital for the community that establishes potential for future competitiveness of lifelong learning and valuable living. The collaboration elements of knowledge management in community-based teachers, as identified by Marquardt (1996), are considered as follows; 1) Acquisition 2) Creation 3) Storage 4) Analysis and Data Mining 5) Transfer and Dissemination 6) Application and Validation (Phanit, 2005)

Due to the matter of fact, social studies teachers, as learning management administrators, have to integrate innovation into diverse contexts and inaugurate community learning development by community, and to community. The author, therefore, studies the designs of community-based transdisciplinary learning for social studies teachers in the diverse school contexts addressed in the northern part of Thailand. Local context is applied as an instruction aimed at articulating skill in transdisciplinary for social studies teachers. It helps to raise awareness and value the preservation of cultural capital approaches social phenomena that exist in the learning area. Additionally, it advocates the development of innovation in community-based transdisciplinary learning appropriately and effectively in diverse school contexts

\section{Objectives}

1) To study problems and the needs in community-based transdisciplinary learning for social studies teachers in the diverse school contexts, Northern of Thailand.

2) To develop and find the efficiency of handbook of community-based transdisciplinary learning for social studies teachers in the diverse school contexts, Northern of Thailand.

3) To examine the implementation results of its handbook.

\section{Theoretical Backgrounds and Theoretical Framework}

\subsection{Transdisciplinary Learning}

Transdisciplinary refers to traverses all possible disciplines (Nègre, 1999; Nicolescu, 1997). The objective of transdisciplinary is to understand the present world, in all of its complexities, instead of focusing on one part of it. A new form of learning and problem-solving involving cooperation among different parts of society, including academia, in order to meet the complex challenges of society (Regeer, 2002). A new intellectual space is formed. Therein resides a gradual cross-fertilization resulting from the convergence of different paths (Lattanzi, 1998). This type of knowledge is globally open and entails both a new vision and lived experiences (Nicolescu, 1997). Lattanzi (1998) argues the valuable first-step knowledge to understand problems from one perspective. Harmonious distribution of resources and the realization of human empowerment and potential through education are best interdisciplinary for treating problems. This is the reason why transdisciplinarity is illustrated as a process appertain to the integration of efforts by multiple disciplines to forward issues or problems with global implications. Kaufman and Moss Osborn (2003) proposes that interdisciplinary learning differs from conventional approaches, or it means something completely new in terms of study content organization and a pupil's self-regulated learning. McWilliam, Hearn and Haseman (2008) describes that a transdisciplinary 
knowledge environment has a greater capacity to inform creative work futures. This emphasis moves transdisciplinary innovation increasing the number of acceptable approaches to students and community (Jantsch, 1972), with hypotheses on a different level of reality and perception.

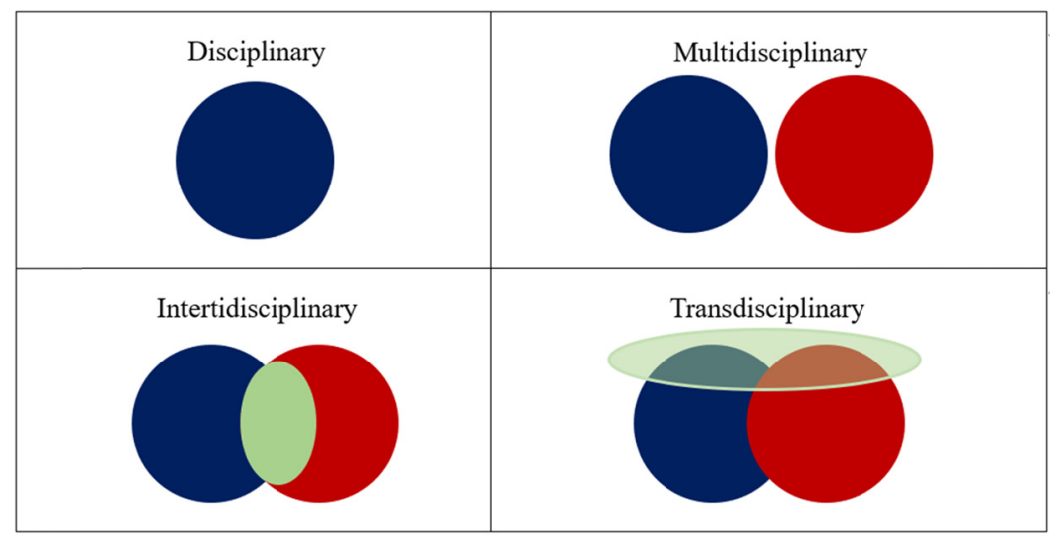

Figure 1. Concept of transdisciplinary learning

Source: adjusted from Carrillo, 2018.

However, it is found that interdisciplinary requires teacher's engagement and collaboration over the idea of sharing to integrate learning experiences which will benefit a consequential and sustainable understanding for students to achieve an effective deep learning and advancing interdisciplinary learning.

\subsection{Transdisciplinary Learning Skills}

The world in which we all live is constantly changing and evolving. Therefore, need to equip our students with sets of relevant skills that help to thrive and adapt in any profession, challenges, or situations they find themselves in. The below skills are deemed transdisciplinary learning, meaning that they are not specific to a particular area or field. Which consists of 5 important skills which are; (McKinnon Primary School, n.d.)

1) Thinking Skills such as acquisition of knowledge, comprehension, application, analysis, synthesis, evaluation, dialectical thought, and metacognition.

2) Social Skills such as accepting responsibility, respecting others, cooperating, resolving conflict, group-decision making, adopting a variety of group roles.

3) Communication Skills such as listening, speaking, reading, writing, presenting, non-verbal communication.

4) Self-Management Skills such as gross motor skills, fine motor skills, spatial awareness, organization, time management, safety, healthy lifestyle, codes of behavior, and informed choices.

5) Research Skills such as formulating questions, observing, planning to collect, organizing and interpreting data, and presenting research findings.

\section{Method}

\subsection{Research Design}

This study was a Mixed Method in Education Research using qualitative research methodology for data collection and data analysis obtained from questionnaires. The quantitative research methodology was used for data collection and data analysis obtained from the assessments, for presentation of the study results of the study in Descriptive Analysis using quantitative and qualitative data for data synthesis and description.

\subsection{Population and Sample Group}

The population used for the study consisted of 2 main target groups: 1) experts in spatial education, and 2) social studies teachers in the northern provinces of Thailand totaling 2,020 people. I selected the sample groups to facilitate data collection and to obtain data from the sample group. The details are as follows:

1) Experts in spatial education to assess the community-based transdisciplinary learning of social studies teachers in schools in different contexts in Northern Thailand. I used Purposive Sampling to obtain data from not less than 5 samples. 
2) Social studies teachers in the Northern-region provinces of Thailand to inquire about needs and problems of the community-based transdisciplinary learning management, as well as the development of a handbook for community-based transdisciplinary learning management of social studies teachers in the diverse school contexts, Northern of Thailand. I used the Accidental Sampling method based on Taro Yamane's sample size criterion (1973). Details are as follows:

$$
\begin{gathered}
\mathrm{n}=\frac{\mathrm{N}}{1+\mathrm{Ne}^{2}} \\
\mathrm{n}=\frac{2,020}{1+2,020(.05)^{2}} \\
\mathrm{n}=333.88
\end{gathered}
$$

Where $\quad \mathrm{n}=$ Sample size

$$
\mathrm{e}=\text { Acceptable sampling error percentage }
$$

Therefore, the representatives of social studies teachers in the northern provinces of Thailand to be collected questionnaire must be at least 334 people.

\subsection{Research Tools}

1) A questionnaire on problems and the needs in community-based transdisciplinary learning to be used for the study of needs and problems in learning management.

2) An evaluation of the handbook for the community-based transdisciplinary learning management of social studies teachers in the diverse schools contexts, Northern Thailand to be used for the verification of the quality of the learning management handbook.

3) An evaluation form of teacher professional competence in community-based transdisciplinary learning of social studies teachers in schools in different contexts of northern Thailand to be used for evaluation of learning management handbook.

For research tools, validity and reliability were investigated by experts in social studies and spatial studies until a systematic conclusion and analysis of the data were obtained.

\subsection{Method of Collecting Data}

1) A documentary study by collecting data from documents, books, journals either relating theory, concept, or research focusing on the information supporting data analysis

2) A field study, steps as considered;

Step 1 Situational Analysis, approaches to qualitative data collecting from related documents and research. The interview of a specified group of social studies teachers in the northern provinces of Thailand, using a questionnaire on problems and the needs in community-based transdisciplinary learning.

Step 2 Design and Development, process to quantitative data collecting by designing, developing, and validating the handbook efficiency provided by educational connoisseurship of area-based. The tools used in this step is an appropriateness assessment form on the handbook to verify its quality and field tryout social studies teachers in the Northern-region provinces of Thailand.

Step 3 Assessing and Evaluating the Handbook, data collected from social studies teachers in the Northern-region provinces of Thailand. The tools used in this step is an evaluation form of teacher professional competence in community-based transdisciplinary learning. This is to evaluate social studies teachers in terms of knowledge, attitude, and learning management skill.

\subsection{Data Analysis}

1) Qualitative Data: The data were analyzed based on the research purpose with content analysis according to the guidelines of Hubbard \& Power's, who established four qualitative data analysis steps: 1) Preparation of data obtained from focus group and questionnaires, 2) Review of research questions 3) Data management by formatting data relationships, and 4) Data analysis by defining the main and secondary issues used for analysis to summarize the issues according to the data group and present the study results in a descriptive form.

2) Quantitative Data: The data obtained from the evaluation were analyzed by a statistical program that can be analyzed efficiently by descriptive statistic. The statistical analysis results were shown as mean and standard deviation. 


\subsection{Trustworthiness and Quality in Studies}

In this study, Basic criteria was used to determine the value of Trustworthiness with the Lincoln and Guba's Trustworthiness Guidelines (1985): 1) Credibility, 2) Dependability, 3) Confirmability, and 4) Transferability. Furthermore, the data are presented to informants and related people to review all stages of the study by inquiring back to a group of informants on various issues as member checking, and familiarize the informants to enable them to behave as phenomenological validity.

\subsection{Ethical Considerations}

To observe the highly confidential nature of the study, no particular names were mentioned in the study. The identity of the respondents was undisclosed. No personal opinions were given by the researchers, only information and results based on the data to be gathered. The research participants should not be subjected to harm in any way the results or findings of the study. The study considered high respect for the dignity of research to be prioritized and full consent should be obtained from the participant prior to the study.

\section{Results}

The results are classified follows specific objectives and presented in 3 dimensions as follows;

5.1 Problems and the Needs in Community-Based Transdisciplinary Learning for Social Studies Teachers in the Diverse School Contexts, Northern of Thailand

It revealed that teacher professional competence needs to be improved in community-based transdisciplinary learning through 7 skills, namely; Integrated learning Management, Technology Integrated Learning, Integrating Ethics Learning, Community Resource Management, Transdisciplinary Innovation Integrated Learning, Creative Educational Measurement Design, and Competency of networking skill.

5.2 The Development of Handbook of Community-Based Transdisciplinary Learning for Social Studies Teachers in the Diverse School Contexts, Northern of Thailand

This study used the operationalization of the "CADDIE Model" framework built by Charin Mangkhang (2018), found that the learning management handbook can be designed and developed into 4 learning units, 25 learning management plans, and 8 learning activities as follow; 
Table 1. Details of the unit and community-based transdisciplinary learning plan for social studies teachers in the diverse school contexts, Northern of Thailand

\begin{tabular}{|c|c|}
\hline Unit of Instruction & Minor Plans \\
\hline Unit of Instruction 1 & 1. What is community resources? Induction method \\
\hline \multirow{7}{*}{$\begin{array}{l}\text { Understanding community } \\
\text { resources, consisting of } 8 \text { learning } \\
\text { plans }\end{array}$} & 2. Social resource context: self-study method (Independent Study) \\
\hline & 3. Community resource management methods: Mind mapping \\
\hline & 4. Resource perspective in our opinion: The Winnetka Plan \\
\hline & 5. Learn community ways-learn together: Participatory learning \\
\hline & 6. Community and resources-Perfect reconciliation: Reconciliation Learning \\
\hline & 7. Community of sustainable happiness: Brainstorming learning and learning through questioning. \\
\hline & 8. Creative product Participatory learning \\
\hline Unit of Instruction 2 & 1. Community Learning \\
\hline \multirow{9}{*}{$\begin{array}{l}\text { Connecting community resources, } \\
\text { consisting of } 10 \text { learning plans }\end{array}$} & 2. Life Story \\
\hline & 3. Genogram \\
\hline & 4. Local History \\
\hline & 5. Community Calendar \\
\hline & 6. Community Organizations \\
\hline & 7. Local Health Systems \\
\hline & 8. Geo-Social Mapping \\
\hline & 9. Story Making by Children \\
\hline & 10. Storytelling About Community \\
\hline Unit of Instruction 3 & 1. Knowing media in everyday life: Importance and media utilization \\
\hline \multirow{6}{*}{$\begin{array}{l}\text { Development community resource, } \\
\text { consisting of 7learning plans }\end{array}$} & 2. Media literacy: Media are taken into consideration creatively \\
\hline & 3. Creative media production: Development of leaflets \\
\hline & 4. Creative media production: Posters for creative areas \\
\hline & 5. Creative media production: Review of social posts \\
\hline & 6. Creative media production: Narrative storytelling (Storyboard) \\
\hline & 7. Creative media production: Video presentation \\
\hline \multirow{8}{*}{$\begin{array}{l}\text { Unit of Instruction } 4 \\
\text { NAWATWITHI citizenship, } \\
\text { consisting of } 8 \text { developing plans of } \\
\text { learning skills }\end{array}$} & 1. Learning goals \\
\hline & 2. Opening areas of learning \\
\hline & 3. Areas of knowledge sharing \\
\hline & 4. Surveying the context of surrounding areas \\
\hline & 5. Living lessons \\
\hline & 6. Strong citizens \\
\hline & 7. Lesson learned \\
\hline & 8. Applying to everyday life \\
\hline
\end{tabular}

Having designed and developed the handbook, essential finding is the outcome of participatory action learning, "SOCIAL Action Learning Model", as having

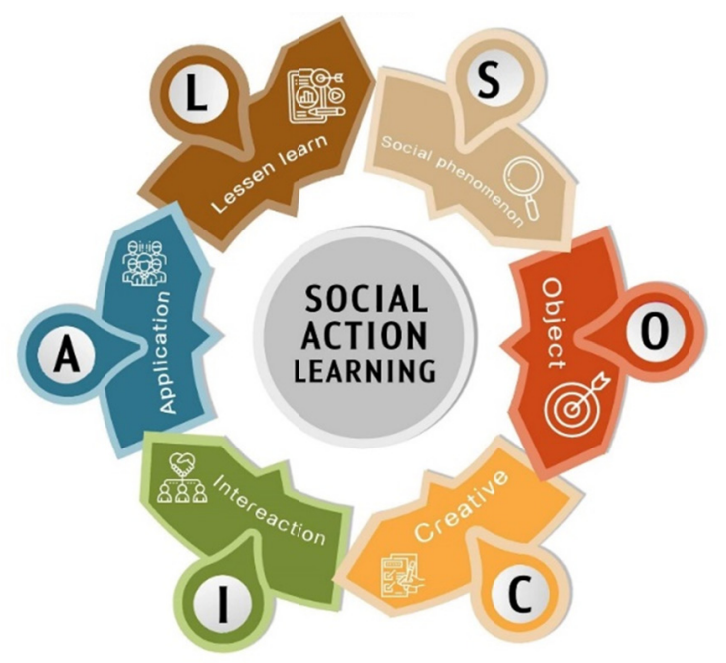

Figure 2. SOCIAL Action Leaning (SAL) 
$\mathbf{1}^{\text {st }}$ step Understanding the Social Phenomenon (S) is to study the context of the community by delivering in harmony in the community area, it is to have understandings of the condition and geography of the community which benefits the research. Moreover, social phenomena also evolve with respect to population as ownership of resources.

$2^{\text {nd }}$ step Defining the Object $(O)$ leads to a specific method or process of learning that can be solidly measured and evaluated. It is deployed to guide students' learning goals and honor once their goals are accomplished.

$3^{\text {rd }}$ step Designing Learning with Creativity $(C)$ through various techniques and methods operation, together with Community-Based Transdisciplinary Learning in Social Studies - the innovative teacher practice to be a leader in changing the community along the strengthening civic engagement of teachers, students, and community members. Social studies teachers must have holistic competency, "Teacherization in Action"

$4^{\text {th }}$ step Enhancing Interaction (I) on learning areas is significant to develop learning innovations in order to broaden perspective and reinforce community engagement to build adequate learning management.

$5^{\text {th }}$ step Knowledge Transfer and Application (A) is the "Success Key" of capable learning that must be consistent with continuous social change, here and abroad, toward an unfamiliar way of learning setting, "New Normal"

$6^{\text {th }}$ step Lesson Learn (L) in area-based education is emphasized in social studies as it encourages critical/appreciative inquiry based on theoretical social and humanities i.e., political history, environment, culture, and so on, interwoven within geographical approach. This demonstrates an outcome utilized to geographical knowledge management and essential organizational diversity learning framework.

As a result of an appropriateness assessment on the handbook of community-based transdisciplinary learning for social studies teachers in the diverse school contexts, Northern of Thailand, from educational connoisseurship of area-based, outcomes obtained as follows;

Table 2. The appropriateness of handbook community-based transdisciplinary learning for social studies teachers in the diverse school contexts, Northern of Thailand

\begin{tabular}{|c|c|c|c|}
\hline Evaluation Particulars & $\overline{\boldsymbol{x}}$ & SD & Interpretation \\
\hline $\begin{array}{l}\text { 1. As a comprehensive Learning Management handbook dealing with strategies of understanding, } \\
\text { achievement, and development }\end{array}$ & 4.73 & 0.45 & Highest level \\
\hline $\begin{array}{l}\text { 2. The handbook guides to develop social studies teachers in terms of knowledge, skill, process, } \\
\text { essential competency, and character education }\end{array}$ & 4.70 & 0.46 & Highest level \\
\hline 3. The handbook is consistent with 21 st Century Education & 4.65 & 0.69 & Highest level \\
\hline 4. The handbook provides different learner-centered approach activities & 4.62 & 0.50 & Highest level \\
\hline 5. Folk media is employed in the handbook for contributing to citizenship strength & 4.59 & 0.60 & Highest level \\
\hline $\begin{array}{l}\text { 6. Local Wisdom and local technology are utilized in the handbook as area-based pedagogical } \\
\text { innovation }\end{array}$ & 4.57 & 0.55 & Highest level \\
\hline $\begin{array}{l}\text { 7. The handbook emboldens domains of learning; the cognitive, the affective, and the } \\
\text { psychomotor domain }\end{array}$ & 4.43 & 0.79 & High level \\
\hline $\begin{array}{l}\text { 8. Student progress is evaluated through multiple assessment methods as suggested in the } \\
\text { handbook which is appropriate to the nature of social studies and area-based learning management } \\
\text { framework }\end{array}$ & 4.35 & 0.59 & High level \\
\hline Perspective & 4.58 & 0.57 & Highest level \\
\hline
\end{tabular}

According to Table 2, it is found as follows; The handbook of community-based transdisciplinary learning for social studies teachers in the diverse school contexts, Northern of Thailand, are suitable at the highest level $(\bar{x}=$ 4.58) which there are in 6 criteria, namely; 1) As a comprehensive Learning Management handbook dealing with strategies of understanding, achievement, and development $(\bar{x}=4.73)$ 2) It guides to develop social studies teachers in terms of knowledge, skill, process, essential competency, and character education $(\bar{x}=4.70) 3)$ It is consistent with 21 st Century Education $(\bar{x}=4.65) 4)$ It provides different learner-centered approach activities $(\bar{x}=4.62)$ 5) Folk media is employed in the handbook for contributing to citizenship strength $(\bar{x}=4.59)$ and 6$)$ Local Wisdom and local technology are utilized in the handbook as area-based pedagogical innovation $(\bar{x}=4.57)$ 


\subsection{The Result of Using Handbook of Community-Based Transdisciplinary Learning for Social Studies Teachers in the Diverse School Contexts, Northern of Thailand}

Table 3. Details of teacher professional competence in social studies teachers of which community-based transdisciplinary learning is investigated in the diverse school contexts, Northern of Thailand

\begin{tabular}{llll}
\hline Evaluation Skills & $\overline{\boldsymbol{x}}$ & SD & Interpretation \\
\hline 1. Integration of Sufficiency Economy concepts into management plan for creative learning & 4.36 & 0.76 & High level \\
2. Integration of technology in education for the strengthening in Green Citizenship & 4.14 & 0.77 & High level \\
3. Integration of Ethics improving Green Citizenship & 4.09 & 0.70 & High level \\
4. Community Resource Management to promote environmental and sustainable development & 4.09 & 0.82 & High level \\
5. Transdisciplinary Innovation Integrated Learning in a joint response to students' diversity & 3.56 & 0.54 & High level \\
6. Creative Educational Measurement Design with regards to help students reach their potential & 4.03 & 0.65 & High level \\
7. Competency of Networking concerning students lifelong learning & 3.47 & 0.70 & Fair level \\
Perspective & $\mathbf{3 . 9 6}$ & $\mathbf{0 . 8 9}$ & High level \\
\hline
\end{tabular}

According to Table 3, it is found as follows; The perspective of teacher professional competence in social studies teachers of which community-based transdisciplinary learning is investigated in the diverse school contexts, Northern of Thailand, is at high level $(\bar{x}=3.96)$ respecting skills, scilicet; Skills that most of social studies teachers have includes skill of Integration of Sufficiency Economy concepts into management plan for creative learning $(\bar{x}=4.36)$, Integration of technology in education for the strengthening in Green Citizenship $(\bar{x}=4.14)$, Integration of Ethics improving Green Citizenship $(\bar{x}=4.09)$, Community Resource Management to promote environmental and sustainable development $(\bar{x}=4.09)$, Transdisciplinary Innovation Integrated Learning in a joint response to students diversity $(\bar{x}=3.56)$, and Creative Educational Measurement Design with regards to help students reach their potential $(\bar{x}=4.03)$, respectively. However, Competency of Networking concerning students lifelong learning is found at fair level $(\bar{x}=3.47)$

\section{Conclusion and Discussion}

1) Problems and the needs: teacher professional competence needs to be improved in community-based transdisciplinary learning through 7 skills, namely; Integrated learning Management, Technology Integrated Learning, Integrating Ethics Learning, Community Resource Management, Transdisciplinary Innovation Integrated Learning, Creative Educational Measurement Design, and Competency of Networking skill. Somsri (2015) sees the need for academic competency development of teachers in educational institutions perspective, due to current conditions, at the highest level toward research and information systems skill, classroom research for student's achievement skill, and construction and development of curriculum skill. In addition, there are problems on pedagogical management in nearly all teachers regarding management of learning activities, the use of innovation communication, and student learning assessment (Suthasinobon, 2016). Recently seven professional teacher competences for social studies teachers, in compliance with guidelines for teacher development, heighten teacher ability of community-based transdisciplinary learning to enhance students' 21 st century skill which merged in the new normal in education under globalization.

2) The result of handbook development: "SOCIAL Action Learning Model" should be implemented in community-based transdisciplinary learning for social studies teachers which includes 6 steps. With highly effective learning management, Rithikup (2018) suggests that students are able to broaden their 21st century skill. Community-based learning, one of examples, a teaching strategy that creates classroom community toward integrated knowledge connected with real issues in everyday life, is an increased focus on skill of critical thinking, problem solving, and experiential learning through participatory action. Lattanzi (1998) and Nicolescu (1997) also describe transdisciplinary as a new kind of knowledge that complements traditional classrooms when a new intellectual space is formed with a variety of knowledge, by specific experts' engagement, to understand the present world in all of its complexities. Those studies also echo Regeer (2002), who notes transdisciplinarity is considered as a new form of learning and problem solving, related to cooperation between different sections of society, including educational institutions, that helps to meet complex challenges of society. In this study, the efficiency of the handbook is appropriate at the highest level $(\bar{x}=4.58$, S.D. $=0.57)$, agreeable to Somsri (2015) papers that the process of highly effective handbook development must be taken participatory action by school teachers, at the highest level of appropriation $(\bar{x}=4.64)$. Therefore, highly effective community-based transdisciplinary learning for social studies teachers through the research process in this study will broaden students' citizenship skill, problem-solving, and learning achievement. 
3) The result of using handbooks: the handbook of community-based transdisciplinary learning for social studies teachers found the evaluation results are at a high level $(\bar{x}=3.96$, S.D. $=0.89)$. Leeraphan $(2005)$ advises handbook development and design should consider factors including problems and needs in the matter of usage, this study, too, situational analysis is conducted formerly to determine its problem and needs in community-based transdisciplinary learning for social studies teachers. By the same token, Chaiwut et al. (2017) cites users' requirements also should be sought for cooperative and practical suggestions to sustain its effectiveness and efficiency. Professional teachers must concern self-development consistently and continuously, respecting integrated learning management, and professional skills, to help students reach their potential genuinely, classroom management, too, to create optimal classroom climate that promotes creative or constructivist learning (Khantitharangkun, 2018). Skills that majority of social studies teachers possess, at high level, are Integration of Sufficiency Economy concepts into management plan for creative learning $(\bar{x}=4.36)$, Integration of technology in education for the strengthening in Green Citizenship $(\bar{x}=4.14)$, and Integration of Ethics improving Green Citizenship $(\bar{x}=4.09)$, respectively.

\section{Research Recommendations}

\subsection{Recommendations for Usage in Research}

1) The Committee of Professional Learning Community (PLC) is recommended in educational institutions for external knowledge sharing.

2) There should be intermittent monitoring and evaluating to investigate the appropriateness and improvements.

\subsection{Recommendations for Future Research}

1) Teachers, administrators of educational institutions and higher education institutions should collaborate in designing policy planning for community-based transdisciplinary learning for social studies teachers, in the diverse school contexts, which renders teaching activities integrated with other courses or subjects for future development of essential students' competency.

2) Community-based transdisciplinary learning in diverse school contexts should be applied in other regional areas of Thailand as well.

\section{References}

Carrillo, J. (2018). Transdisciplinary Education: Learning that is Authentic and Relevant. Retrieved September 19, 2020, from https://www.magellanschool.org/transdisciplinary-education-approach-learning-authentic-relevant-real-wor ld/

Chaiwut, S. et al. (2017). The development of academic management handbook for Faculty of Education, Chiang Mai Rajabhat University. Ganesha Journal, 13(2), 129-147.

Hubbard, R. S., \& Power, B. M. (1999). Living the questions: A guide for teacher-researchers. Portland, Maine: Stenhouse.

Jantsch, E. (1972). Inter- and trans-disciplinary university: A systems approach to education and innovation. Higher Education, 1(1), 7-37. https://doi.org/10.1007/BF01956879

Kaufman, D., Moss, D. M., \& Osborn, T. A. (2003). Beyond the Boundaries: A Transdisciplinary Approach to Learning and Teaching. Praeger. Westport, CT.

Khantitharangkun, S. (2008). Professional Teacher Class Management. Journal of Education, Loei Rajabhat University, 1(2), 1-19.

Lattanzi, M. (1998). Transdiscipliarity at UNESCO. Retrieved September 19, 2020, from http://www.Unesco.org/philosophy/en/transdisciplinarity/transdoc.htm

Leeraphan, P. (2005). Construction of performing job handbook for personnel in the service of academic and research, Faculty of Dentistry, Chiang Mai University. Chiang Mai: Chiang Mai University.

Lincoln, S. Y., \& Guba, E. G. (1985). Naturalistic inquiry. Thousand Oaks, CA: Sage. https://doi.org/10.1016/0147-1767(85)90062-8

Mangkhang, C. et al. (2015). The Development of Local Curriculum on Miang Thepsadej, Doi Saket District, Chiang Mai Province. Chiang Mai: Chiang Mai University.

Marquardt, M. J. (1996). Building the Learning Organization: A System Approach to Quantum Improvement and Global Success. New York: McGraw-Hill. 
McKinnon Primary School. (n.d.). Approaches to Learning/Transdisciplinary Skills. Retrieved September 19, 2020, from https://mckinnon-primary.vic.edu.au/pyp-news/transdisciplinary-skills/

McWilliam, E., Hearn, G., \& Haseman, B. (2008). Transdisciplinarity for creative futures: What barriers and opportunities? Innovations in Education \& Teaching International, 45(3), 247-253. https://doi.org/10.1080/14703290802176097

Nègre, A. (1999). A transdisciplinary approach to science and astrology. Retrieved September 19, 2020, from http://cura.free.fr/quinq/02negre2.html

Nicolescu, B. (1997). The transdisciplinary evolution of the university condition for sustainable development. Retrieved September 19, 2020, from http://persoclubinternetfrnicolciretbulletin/b12/b12c8.htm

Phanit, W. (2005). Knowledge management: Operator version. Bangkok: Sukhaphabjai.

Regeer, B. (2002). Transdisciplinarity. Retrieved September 19, 2020, from http://www.bio.vu.nl/vakgroepen/bens/HTML/transdiscipliNl.html

Rithikup, W. (2018). Community-Based Learning: Effective Pedagogy Strategies for Teachers in the 21st Century. Graduate School Journal, 11(3), 179-191.

Smith, G. (2005). Green Citizenship and the Social Economy. Environmental Politics, 14(2), 273-289. https://doi.org/10.1080/09644010500055175

Somsri, M. (2015). Manual Development on Teacher's Academic Competency in Schools under the Office of Udonthani Primary Educational Service, Area 2. Journal of Education, Mahasarakham University, 9 (Special ed.), 542-557.

Suthasinobon, K. (2016). The Development of Teachers' Skills of Buddhist Instruction for Schools Affiliated with the Nakhon Nayok Primary Educational Service Area Office under the Royal Project. Journal of Education Research, Faculty of Education, Srinakharinwirot University, 10(2), 1-17.

Taro, Y. (1973). Statistics: An Introductory Analysis (3rd ed.). New York: Harper and Row Publications.

\section{Copyrights}

Copyright for this article is retained by the author, with first publication rights granted to the journal.

This is an open-access article distributed under the terms and conditions of the Creative Commons Attribution license (http://creativecommons.org/licenses/by/4.0/). 